\title{
The early days of insulin use in Edinburgh
}

\author{
Rae Ll Lyon
}

The Royal Infirmary of Edinburgh has long been associated with the treatment of diabetes mellitus, particularly with diet and insulin. This has been due more to the teams of workers who came together than to individual specialists, but even more so to the initial impetus when insulin was discovered.

Before insulin was successfully isolated by Banting the existence of an internal secretion of the pancreas that would influence carbohydrate metabolism had been postulated. In fact it had been named in 1916 by Sir Edward Sharpey-Schaffer, the professor of physiology in Edinburgh University.

At the end of the first world war it was decided to establish a chair of therapeutics in Edinburgh, and the appointment went to Jonathan Campbell-Meakins, a Canadian who had been in London before the war with Sir Thomas Lewis and Sir James Mackenzie and again on war service. He showed a research instinct with a strong physiological bias in his clinical practice. With the appointment came an offer to establish a laboratory for biochemistry and for physiological investigation.

When Meakins took up his duties in October 1919 the other members of the team were David Murray Lyon, assistant physician, and Charles George Lambie, clinical assistant. About this time Chas Harington (later Sir Charles) and William Robson, who were both working with Professor Barger (in medical chemistry), were added to the team as biochemists. Even before the arrival of insulin they were interested in diabetes and writing about it. ${ }^{12}$ Their main treatment was with the Allen regimen of controlled starvation.

In November 1921 Meakins was granted leave of absence to join in experiments on respiratory physiology at high altitude in Peru. He wrote in his unpublished autobiography that on returning through Canada about February 1922 he "heard rumours about a spectacular advance in the control of carbohydrate."

It will be remembered that Banting and Best started their work together in May 1921 and treated their first patient in January 1922. Banting announced his

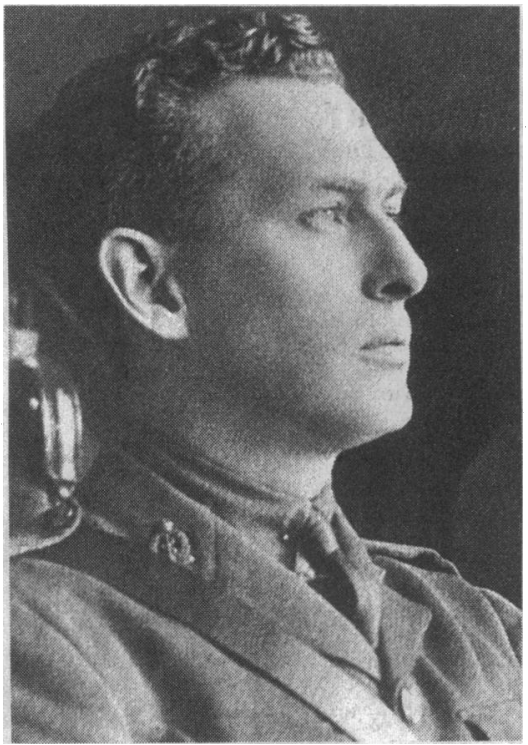

Professor Fonathan Campbell-Meakins, 1919

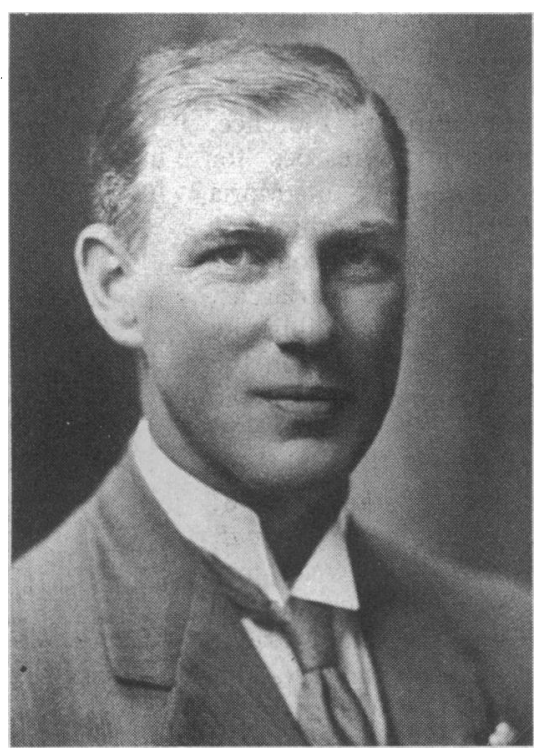

Professor David Murray Lyon, 1924 discovery on 7 February 1922 in an address to the Academy of Medicine of Toronto. Meakins's account of his impressions of this time are worth quoting in detail.

"In the March 1922 number of the Canadian Medical Association Journal was a report of the successful treatment of seven cases of diabetes in man.... So we decided to try our hand at it. Harington was sure we could succeed.... So we started it with our grinding stage, using pig pancreases in a basement of one of the wards of the Infirmary as our workshop.... It was not long before Harington had what he believed to be a potent insulin, but we had to try it. We dared not do this on man and we could not house rabbits in the Infirmary so we got a few into Professor Barger's laboratory and a few more with Professor Cushney [pharmacology]. Our first batch was so potent that we killed the rabbits, but by dilution we came to a level that both Barger and Cushney thought was safe. So we quietly almost surreptitiously - sought for volunteers. Among the first to respond was Professor Norman Walker. He entered the public ward and after standardisation of his fasting blood sugar we gave an injection with our hearts in our mouths and intravenous solutions of glucose at hand. The result was perfect."

Norman Purves Walker had been appointed physician to the skin department in 1906 . He was knighted in 1923 when he became president of the General Medical Council. During the first world war he developed diabetes but was able to control it by diet. It was thought by his family that the impoverished wartime rations kept him well, but it now seems more likely that he belonged to that interesting subgroup who, starting their diabetes in middle age, have a prolonged "honeymoon period" before showing frank insulin dependency. Soon after the war he visited India, and it was on his return that his diabetes really began to affect him and his condition started to deteriorate. He survived until November 1942. Many years later Dr Willie Bethune, who qualified at Edinburgh in 1923, described how Norman Walker became gradually weaker until he had to be carried into the theatre and lecture his students sitting down, but after insulin was started his energies were renewed.

Meakins wrote to Professor J J R MacLeod of Toronto on 17 June 1922 requesting supplies of insulin for Dr Norman Walker by name. In his reply MacLeod said that it would be useless to send it so far (by surface mail) because "the potency declines after a week or so." He did, however, send very detailed directions for making it. He suggested that one rabbit dose twice daily would usually have a decided effect. On 25 July 1922 Meakins again wrote to MacLeod and planned to send Lambie to Toronto in the middle of August for a few. weeks' sojourn at "insulin headquarters." Lambie is credited with bringing the first supply of insulin into Great Britain (Royal College of Physicians of Edinburgh, Minutes 1960-2, p180).

The ward register of the Royal Infirmary shows that Dr Norman Purves Walker was admitted to Ward 26, Royal Infirmary of Edinburgh, under Professor Meakins between 27 July and 31 August 1922. This is more than likely to be the admission of the first 


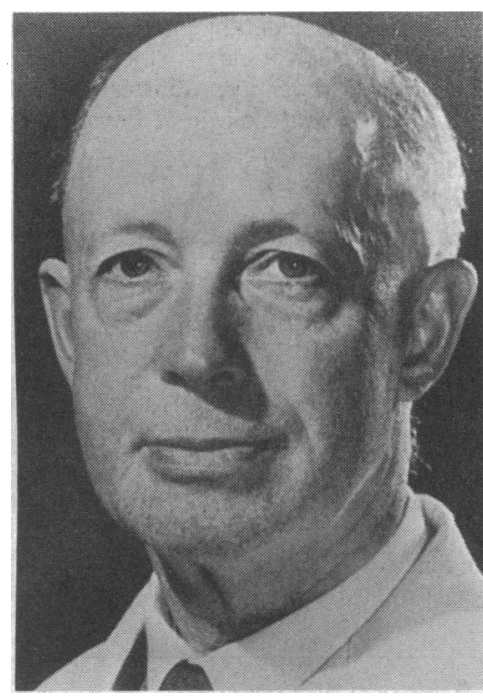

Professor C G Lambie, 1950

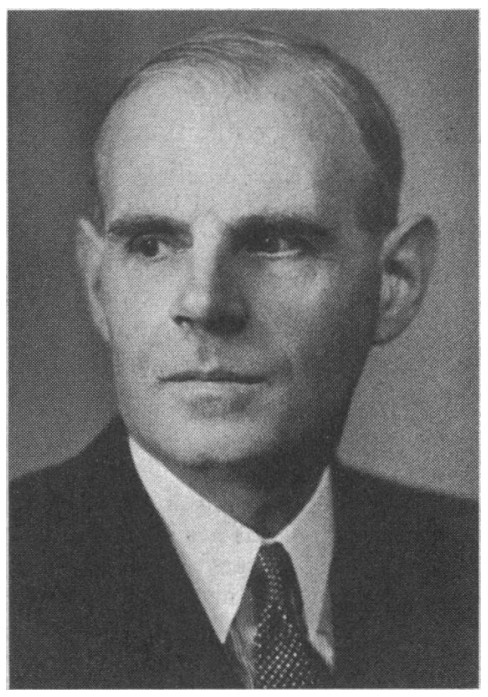

Dr Charles Harington, 1945

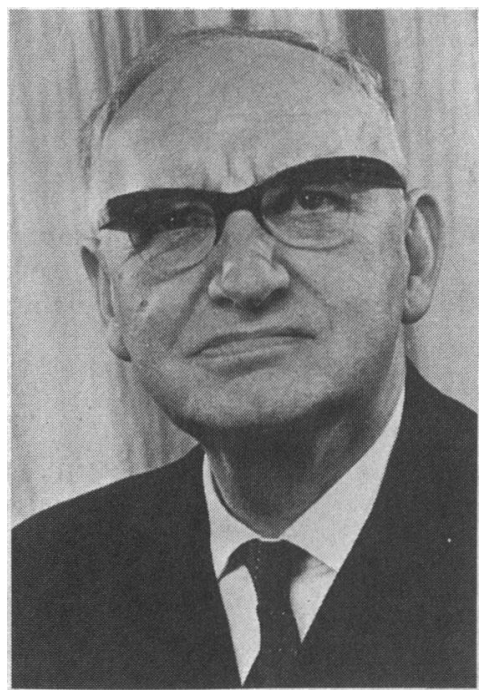

Dr William Robson, 1963 volunteer and the time when "the result was perfect." Thus the first insulin injection in Edinburgh was given in the first week or two of August 1922, almost at the same time as Joslin's first injection on 6 August 1922 in Boston. ${ }^{3}$ As Dr R Carrasco-Formiguera in Barcelona did not give his first injection of homemade insulin until 3 October 1922 he does not seem to be the first European to use insulin. ${ }^{3}$

Another patient who can look back on the early days of insulin in Edinburgh spent his working life as a surgeon. ${ }^{+}$Developing diabetes in 1919 at the age of 7 , he was on starvation diets but went into a nursing home where he was started on 25 units thrice daily. During his stay between August and December 1923 he met an old Edinburgh doctor "who had been making his own insulin and I do recall that it was not very sterile as he got many septic areas after the injections. I think he was an eye specialist attached to the Royal." This sounds very like Dr Walker as recollected by a small boy.

At a time when medicine had so little to offer diabetic patients, and when therapeutics was to a great extent nihilistic, the advent of insulin demanded a complete rethinking of attitudes. Insulin was a dangerous substance that could be given only by injection and therefore had to be controlled chemically at a time when the required knowledge was limited to only a few doctors. The patient was given the responsibility of testing the urine accurately and supervising regular injections.

By June 1922 they had become convinced of the importance of insulin and had a roll of some forty cases of diabetes, thoroughly investigated and treated by the ordinary Allen method. The work was shared in the department, with Dr Murray Lyon in charge of the clinical side, diets, and physiological observations, while Dr Lambie devoted his time to standardisation of the extract, animal experiments, and some physiological and pharmacological work. Mr Robson was responsible for preparing the extract. Meakins himself "had many other duties and research work to supervise but endeavoured to spend as much time as possible upon it."

In the latter part of 1922 they must have been feeling their way, becoming familiar with insulin, its actions, and how to use it. They pushed ahead with their production and clinical investigation. "As we had no place to house animals ... we used humans ... as our. test subjects.... We kept plugging away and learned by experience many things the hard way. The supply of our own product was limited in amount and varied in potency but this latter taught us a lot." Judging from the letters to the Medical Research Council, it may not have been until January 1923 that they were ready to start treating patients regularly.

Professor Cushney warned against hypoglycaemia and asked to have a trained person at hand. "So we trained Sister Pybus who could do a venous puncture better than most residents and was as clever as could be in detecting the first symptoms. She was a jewel beyond price."

On 14 April 1923 the MRC questioned the production of insulin at local hospitals for their own clinical use. Commercial supplies had become available in Britain.

In spite of all these difficulties, in May 1923 the team published a paper on insulin in acidosis and lipaemia, and the next year Murray Lyon published two full accounts of insulin treatment, ${ }^{67}$ the details of which are worth attention and still make good sense. In 1927 Lambie gained his MD with a gold medal for his thesis on the locus of insulin action.

One of the main difficulties was finding that the dietary restrictions of Allen were not sufficiently accurate to balance this new found insulin, so the team set to and extended the developing science of dietetics. Sister Pybus and Dr Murray Lyon started counting calories and weighing diets for their diabetic patients in the ward kitchen. They were calculating diets individually and this was too time consuming, so a series of standard diets was developed for the various stages of treatment. The dietary foundations for treatment of diabetes laid at this period stood for a long time, being commended and reiterated in 1938 by Professor D M Dunlop, ${ }^{8}$ who followed Professor Murray Lyon in the chair of therapeutics.

Meakins continues his account: "With the increasing supplies of insulin we could accommodate many more patients. This became embarrassing." In November 1923 he requested space for diabetic patients. Sister Pybus was appointed senior dietitian five months later when the diabetic outpatient department was started under her, the first of its kind in Britain.

When Professor Meakins resigned in October 1924 he was succeeded by Murray Lyon, who continued to develop the services, and to him "should go the credit for the development and scope of the Dietetic Department as it is today." By now insulin was being widely used in Britain, and yet there was no adequate dietetic knowledge to support it, so Sister Pybus started a six month course in practical dietetics for trained nurses in 1924.

Gradually much more awareness developed of the place of suitable diets in the care of medical and surgical conditions, but still there were insufficient numbers of dietitians. This led in 1934 to the School of 
Dietetics being opened in the Royal Infirmary under the direction of Miss Pybus and sponsored by Professor David Murray Lyon. This was again a first for Edinburgh, though it should be mentioned that a course of diatetics had been provided from 1927 at the Glasgow and West of Scotland College of Domestic Science. ${ }^{10}$

During the past 50 years treatment for diabetes has developed and methods have been modified. The Edinburgh School has made its useful contribution to this progress, and it seems worth while to salute those pioneers who supplied the initial impetus when insulin was discovered.

I thank Professor Michael Bliss, Toronto, for help and encouragement and the following archive departments for making copies of their records available: the University of Toronto for the MacLeod papers; MRC for correspondence with J C Meakins; Edinburgh University Library for access to the general register of patients. The manuscript of Professor J C Meakins's memoirs is held in the Osler Library, McGill University, Montreal. Miss J P S Ferguson, librarian to the Royal College of Physicians, Edinburgh, also gave valuable assistance.

1 Lyon DM, Meakins JC. The treatment of diabetes mellitus. Edinburgh Medical foumal 1921;27:270-85.

2 Lyon DM. Xanthoma diabeticorum. Edinburgh Medical fournal 1922;28: $168-74$.

$3^{\circ}$ Bliss M. The discovery of insulin. Edinburgh: Paul Harris, 1983.

4 Haines T. Discovery of insulin came in the nick of time for surgeon. Hospital Medicine 1983;33:10-1.

5 Davies HW, Lambie CG, Lyon DM. The influence of insulin on acidosis in diabetes. $B M \mathcal{F} 1923 ; \mathrm{i}: 847-9$.

6 Lyon DM. The use of insulin. Lancet 1924;ii: 158-62.

7 Lynn DM. Standard diets for use in diabetes. BMF 1924;ii:326-9.

8 Dunlop DM. Dietetic treatment of the average diabetic. Edinburgh Medical Journal 1938;45:415-34.

9 Buchan A. Growth of the dietetic department. Nutrition 1954;8:72-7.

10 Hutchinson E. History of the British Dietetic Association. London: Newman, 1961.

\section{The medical muse}

\section{Fritz Spiegl}

4 Windermere Terrace, Liverpool L8 3SB Fritz Spiegl, ARAM, musician, writer, and broadcaster

$\operatorname{BrMed}$ f 1990;301:1454-6
Eighteenth century doctors make music-on close stool drums, glyster pipe bassoon, and syringe flageolet

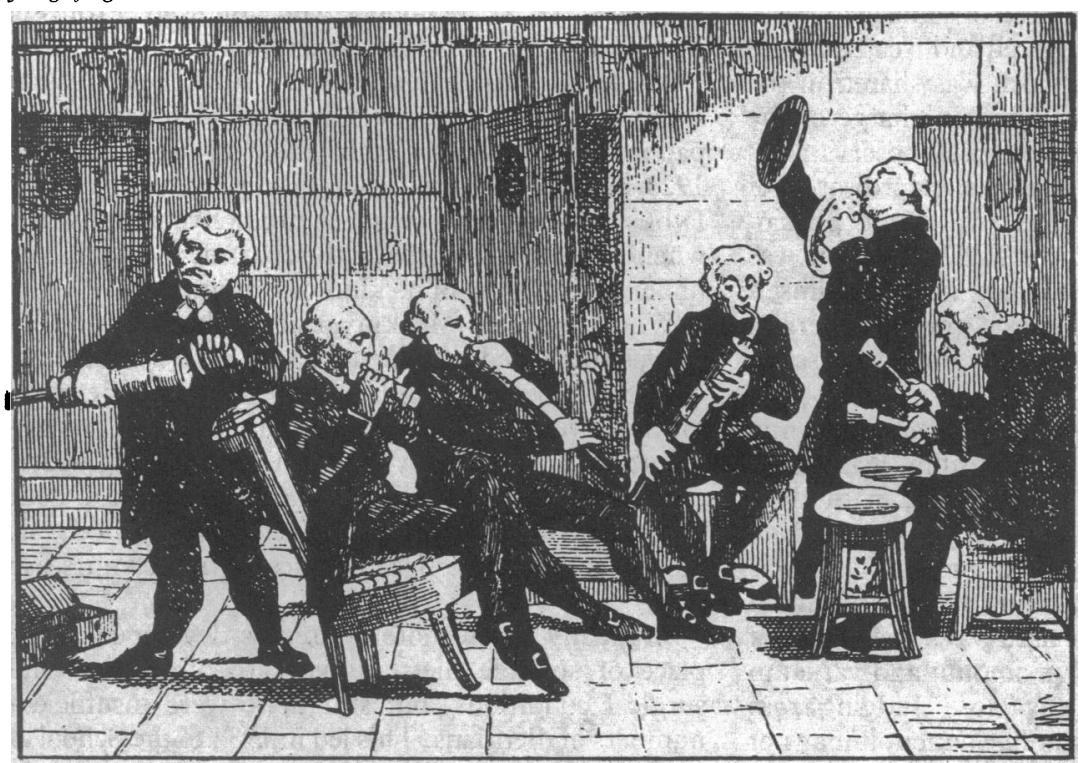

It has long been held-probably since Pythagorasthat an aptitude for music goes hand in hand with a mathematical mind. Indeed there are many distinguished mathematicians who excel in music, but my own observations suggest that musical accomplishment is more widespread among doctors than in any other thinking profession. Perhaps Bacon had the right idea.

The ancients did well to conjoin music and medicine, because the office of medicine is but to tune the curious harp of man's body.

That was long before anyone demonstrated any scientific basis for music therapy.

If you require evidence look around you and listen. The country-no, the world-seems to be full of musical doctors. Many people of my generation who listened spellbound to Boyd Neel and the pioneering English chamber orchestra that bore his name were unaware that he was in fact a music loving doctor. His musical descendant, Jeffrey Tate of the English Chamber Orchestra, also started life as a medical man.

\section{Three medical bassoonists}

When I was a music student one of my own earliest appearances as a soloist was under the baton of Dr Dolf

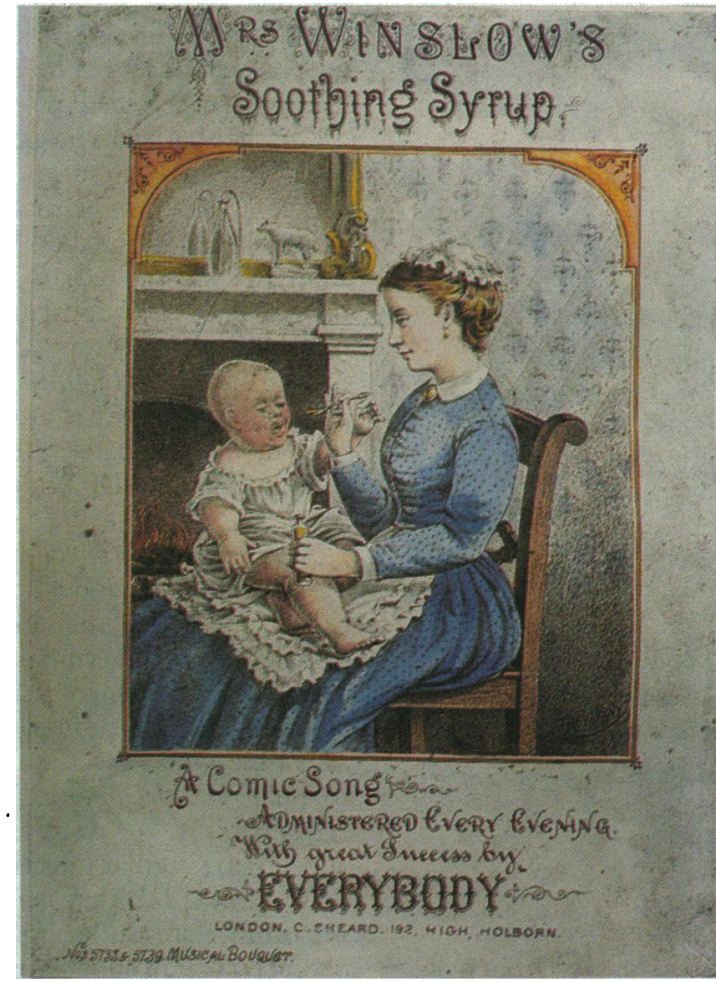

“Mrs Winslow's Soothing Syrup”

Polak of King's College Hospital. On that occasion in the 1950s he also guided Alfred Deller through a Bach cantata. I used to play in an amateur orchestra whose bassoon section was manned by three medical scientists - each one a fellow of the Royal Society-led by the Cambridge pathologist William Rushton.

University orchestras, although diminishing under the onslaught of discothèques and the general stultification of the Walkman battered, cloth eared young, still somehow manage to absorb their usual high proportion of musical doctors. Time and again it has been noticed that children who are subjected to the early discipline of mastering a musical instrument are academically brighter and develop a greater capacity for learning, not least eye and muscle coordination.

I sometimes wonder how all these multitalented doctors find the time. The flautist and conductor (and one time musical arranger for the King's Singers) 